\title{
Integrating Data Mining Into Managerial Accounting System: Challenges and Opportunities
}

\author{
Yihan Wang, Zhenkun Wang \\ Nanjing University of Finance and Economics, Nanjing, China
}

\begin{abstract}
Data mining involves extracting information from large data sets, discovering the hidden relationships and unknown dependencies, and supporting strategic decision-making tasks. The alignment of data mining and business would bring benefits to the organization's management. The study investigated the adoption of data mining technologies in managerial accounting system, concentrating on the challenges and opportunities. The research showed that with the technology adoption, managerial functions could be improved and current information system could be upgraded. Since the technical progresses are reshaping the world of business and accountancy, it is significant for accountants and finance professionals to exploit information technologies.
\end{abstract}

Keywords: data mining, management accounting, accounting information system

\section{Introduction}

With the rapid development of Information Technology (IT) and the popularization of Internet applications, the technology innovations, such as big data and cloud computing, have exported from IT industry to others gradually. The big data of high volume which cannot be collected traditionally are getting into use. These data can be cut, managed, processed, and organized in order to assist business decisions and other purposes. In this process, data mining is the core technology, which can capture and extract more valuable information from markets, therefore it provides an effective backup for decision-makers and strengthens business competitive advantage. As the technologies are evolving in an incredibly high speed, organizations, business, and people should be aware of such technological developments and explore business intelligence, management models, and talents with the aid of IT.

In 2013, the Association of Chartered Certified Accountants' (ACCA's) Accountancy Futures Academy and Institute of Management Accountants (IMA) published a report named "Digital Darwinism: Thriving in the Face of Technology Change". According to this report, the global accountancy profession will be reshaped by 10 technology trends: mobile, big data, artificial intelligence and robotics, cyber security, educational, cloud, payment systems, virtual and augmented reality, digital service delivery, and social. In order to adapt to the new digital environment, accounting professionals need to develop new skills and competencies. Table 1 listed the skills needed for next decade, based on ACCA and IMA members' survey.

Yihan Wang, M.Sc., Nanjing University of Finance and Economics, Nanjing, China.

Zhenkun Wang, Ph.D., Nanjing University of Finance and Economics, Nanjing, China.

Correspondence concerning this article should be addressed to Yihan Wang, School of Accounting, Nanjing University of Finance and Economic, 3rd Wenyuan Road, Nanjing, Jiangsu, 210023 China. 
Therefore, it is significant for professionals to study the integration of technologies and business world. This paper focuses on data mining, one of these technologies, and investigates how to integrate it into management accounting system, especially the changes in managerial functions and information system. The research not only shows one of the applications of data mining technology, but also promotes the digitalization of managerial accounting.

Table 1

Skills Needed for Next Decade

\begin{tabular}{ll}
\hline Rank & Skill \\
\hline 1 & Knowledge of data extraction tools in the mining of business intelligence \\
2 & Use of tools that support data modelling and analysis \\
3 & Knowledge management skills \\
4 & Project management skills \\
5 & Change management skills \\
6 & Knowledge of new approaches to funding and product development \\
7 & Ability to use technology to attract, develop, and manage talent \\
8 & Knowledge of emerging payment platforms \\
9 & Better working knowledge of connectivity and IT security \\
10 & Knowledge on how applications integrate \\
\hline
\end{tabular}

Source: Retrieved from http://www.accaglobal.com/content/dam/acca/global/PDF-technical/other-PDFs/Five-mins-on-DigitalDarwinism.pdf.

\section{Literature Review}

The demand for management information and accounting information promotes the application of IT in business world. The technology innovations in IT sector, such as cloud computing and big data, have become a main driving factor for the development of Management Information Systems (MIS) and Accounting Information Systems (AIS). Data mining, part of the Knowledge Discovery in Database (KDD) process, involves extracting information from large data sets, discovering the hidden relationships and unknown dependencies, and supporting strategic decision-making tasks (Fayyad, Piatetsky-Shapiro, \& Smyth, 1996). This part is based on the literatures of data mining, management accounting, and their integrations.

\section{Data Mining}

Data mining refers to the computational step of inferring theories or patterns from large sets of data (Piatetsky-Shapiro \& Frawley, 1991). The primary goal of data mining is to extract information and knowledge from large quantities of data through automatic or semi-automatic analysis (Han, Kamber, \& Pei, 2012). This involves the exploitation of database techniques, computational science, and statistical theories.

Common data mining methods include cluster analysis, decision tree, genetic algorithms, association rule learning, regression analysis, sequence mining, online analytical processing (OLAP), etc. The main application domains of data mining are data warehouse, decision support system, web mining, predictive analytics, and business intelligence (Tan, Steinbach, \& Kumar, 2011; Han et al., 2012).

In big data era, cloud computing provides infrastructure and services for data storage, while the core data processing technology could be data mining (Chen, Mao, \& Liu, 2014). With the aid of big data technologies, large amounts of financial and non-financial data from business world can be collected and stored in data warehouse for further analysis. These data are massive in quantity and variety. They could be structured data, for example, business transactions, invoices, and cost figures; they could be unstructured data, for example, 
pictures and videos of consumer behaviors. The task for data mining is to extract information from these data, reveal the hidden relationships and patterns, discover the unknown business strategic information, and support decision making process (Labrinidis \& Jagadish, 2012; O’Brien \& Marakas, 2011).

\section{Management Accounting and Managerial Functions}

According to the IMA (2008), management accounting is defined as follows: "Management accounting is a profession that involves partnering in management decision making, devising planning and performance management systems, and providing expertise in financial reporting and control to assist management in the formulation and implementation of an organization's strategy". Therefore, compared to financial accounting, management accounting is more focusing on value-creation, decision making, planning and forecasting, and control and risk management. It involves the organization's value chain operations, such as logistics, marketing, pricing, auditing, and information management. Furthermore, according to International Federation of Accountants' (IFAC's) definition of enterprise financial management, managerial accounting is associated with higher value and more predictive information. As shown in Figure 1, there are three main functions of managerial accounting, i.e., costing accounting, performance evaluation and analysis, and planning and decision support (Professional Accountants in Business Committee, 2009).

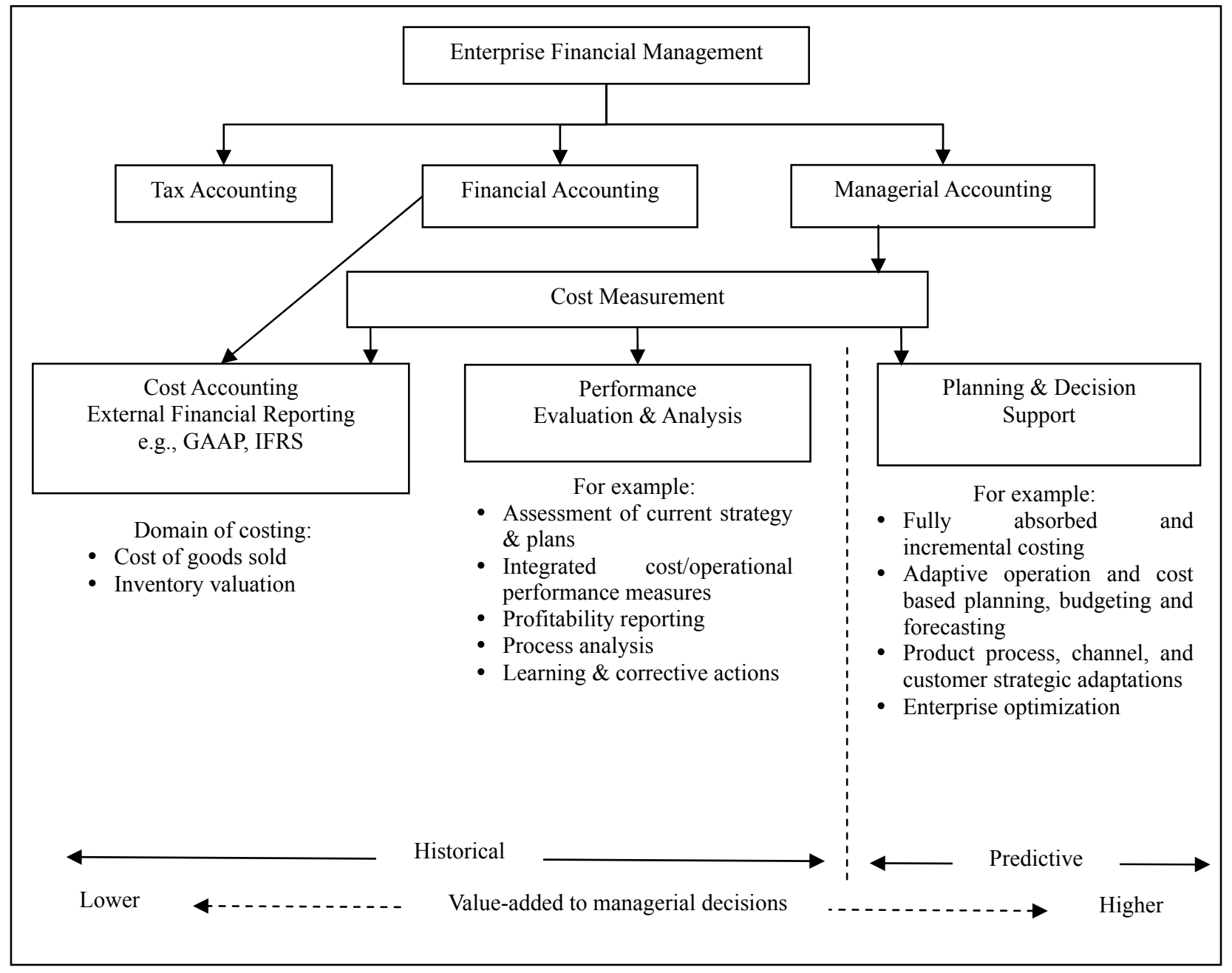

Figure 1. IFAC definition of enterprise financial management. 


\section{Data Mining for Business and Accounting}

Currently, there are many researches on integrating IT, especially big data and data mining, into business world (Varajão, Trigo, \& Barroso, 2009; Lankhorst, 2013; Trigo et al., 2011), for example, Medri (2013) analyzed lots of examples of using data mining technology to predict consumer behaviors and promote one-to-one marketing or target marketing. Besides, business process mining is an emerging research stream, which employs data mining to validate business process implementation (Jans, Alles, \& Vasarhelyi, 2013). Especially for accountancy and finance, Belfo and Trigo (2013) recognized some important challenges in this field and linked technological approaches with them to provide adequate answers to these challenges. They specified data mining as one important technological answer to four challenges, namely "combine historical and current cost accounting", "more non-financial performance data", "tailor-made and interactive reporting", and "internal auditing and internal controls and risk management".

In the area of managerial accounting, there are still a lot of studies about integrating data mining technology. Bode (1998) identified neural network architectures for research and development management application, especially cost estimation. He argued that when the ratio between the highest and the lowest cost is small, the neural networks based on the standard back-propagation learning algorithm perform reasonably well. Edwards (2000) pointed out that the alignment of data mining and cost management would be a trend in the future, aiming at the improvement of cost management intelligence. However, he did not present any practical application model. Bellomi, Cuel, and Biscaro (2005) developed a semantic based software system for monitoring and managing enterprise purchase processes, in order to reduce the purchasing costs. Wijnmalen (2007) analyzed benefits, opportunities, costs, and risks with analytic hierarchy process/analytic network process (AHP/ANP) synthesis, which can produce sound results when assessing the profitability of a project. Ziegler (2012) investigated mining and exploring customer feedbacks with the aid of language models and tree-maps. He proposed natural language processing models and clusters to extract refined information from massive amounts of unstructured data, in order to investigate the topic of interest.

Considering these literatures, there are several issues about the researches on data mining and managerial accounting. Firstly, most of studies are from the practical perspective and researchers tend to develop data mining methodologies to solve real business problem. Secondly, how to integrate data mining into current MIS is not given. Thirdly, technologies and skills are magnified; the art of management is omitted. Technologies are assistant tools for management and accountancy. Their integration into business world still needs to be discussed. This paper attempts to examine the alignment of data mining and management accounting from system and function perspectives, in order to make the most use of technologies.

\section{Research Methodology}

\section{Research Problem}

The problems that this paper attempts to investigate include:

(1) What are the changes of managerial accounting with the adoption of data mining?

(2) Is the technology adoption favorable?

(3) How to implement data mining into current AIS?

\section{Research Design}

Given the aim of understanding data mining adoption and managerial accounting functions in successful organizations, the research approach in this paper is exploratory and documentary-based. The sample consists 
of most relevant papers and studies about data mining and technology adoption in accountancy and business administration. Therefore, this research is concerned not only with the integration of data mining into business decision-making process, but also with the creation of management accounting information and the change of managerial accounting functions. The following parts of this study are structured on: (1) the impact of data mining on management accounting from function perspective; (2) the assessment of technology adoption using "strength, weakness, opportunity, threats (SWOT)" analysis; and (3) possible expansions of current AIS.

\section{Changes of Managerial Accounting Functions}

\section{Cost Management}

The core information that provided by management accountants is the cost figures. Cost management takes an important part not only in planning and budgeting, but also in business strategic decision making process (Lum, Baker, \& Hihn, 2008). Currently, the calculation of cost figures is mostly based on the internal business operations (Lanen, Anderson, \& Maher, 2013). In addition, data about suppliers, partners, or even competitors are needed to support business strategic management. These data sets may be rough, large volume, semi-structured, or unstructured, different from internal data sets. Therefore, data mining could be useful for analyzing these data sets. In big data era, it is likely that cost management would expand to the industry supply chain (Eklin, Arzi, \& Shtub, 2009).

Although the data mining algorithms and empirical models are various and a suitable cost calculation method needs to be selected, the data mining capability can be built up gradually in reality with rules setting and the application of different methods. The final proposed model could be repeatable, robust, and accurate. Besides, data mining needs to be supported with available and comprehensive business or manufacture process data for implementation (Sajadfar \& Ma, 2015).

\section{Performance Evaluation and Risk Control}

The applications of data mining in performance evaluation are diverse, for example, Ren, Yan, and Hong (2015) proposed that data mining is a powerful tool to identify behavioral patterns in building data sets and they took decision tree to link comfort demand and system performance with heating energy use. Xing, Guo, Petakovic, and Goggins (2015) presented how to use data mining approaches to evaluate and predict educational performance. Zhou, Lu, and Fujita (2015) investigated the performance of several financial distress prediction models with features selection guided by data mining techniques and domain knowledge.

In addition, considering the applications of data mining in risk control, banking industry and financial risks are mostly to be referred to. Koyuncugil and Ozgulbas (2012) presented an early warning model based on data mining for financial risk detection, which was helpful not only for enterprises to detect early signs but also for economists to monitor the countries financial risk. Koutanaei, Sajedi, and Khanbabaei (2015) offered the data mining approaches and the feature selection algorithms to improve the banks' performance in credit scoring problems, considering the credit risks of their customers.

Therefore, as the basic functions of management, performance evaluation and risk control play an importance part in business administration. In order to analyze and evaluate performance, it is important to determine the objectives and principles for evaluation. Because data mining aims to find hidden relationships and patterns, the objectives to evaluate performance could combine with a variety of goals, apart from sales rise 
and cost reduction. Besides, the application of data mining in risk control is useful for organizations to detect unknown risk factors and improve their level of risk management.

\section{Planning and Prediction}

The integration of data mining on planning and prediction process is characterized in different industries. Williams and Gong (2014) suggested that some words and phrases are associated with the level of project cost increase. They combined text information and numerical data extracted from text mining to predict cost overruns based on data mining algorithms. Ortiz-Servin, Cadenas, Pelta, Castillo, and Montes-Tadeo (2015) showed that data mining methods can be used to predict fuel lattices operations. Shi, Liu, Shen, Yuan, and Huang (2015) proposed an effective approach to mine web data records, which can extract information from semi-structured web data objects. It is useful for meta search, comparative shopping, etc., therefore it can predict customers preference.

Planning, budgeting, and predicting are the basic managerial functions that can be found in almost every step of business processes. The accuracy of planning and prediction is based upon the analysis of information, for example, production plans are mostly based on historical sales data and the expected profits. In big data era, the models for analyzing expected sales could include additional factors, such as customer behaviors, cultures, and competitors of target markets. The information will contribute to a better prediction and therefore a thoughtful strategic decision.

In practice, different new informations about the organizations operation and the external markets can be arrived at any time. The adoption of data mining technologies would contribute to the analysis of the up-to-date information and improve the accuracy of forecast.

To sum up, the original approach to management accounting is mainly based on mathematical assumptions and structured problem-solving techniques (Lanen et al., 2013). As the business world is full of uncertainties and risks, data mining would be contributable to the analysis of large and/or total sample with unstructured and/or semi-structured data, in order to identify hidden relations and tendencies; therefore, it would strengthen the functions of management accounting and improve the level of business management.

\section{SWOT Analysis of Data Mining Adoption}

SWOT analysis is a structured approach to evaluate the strengths, weaknesses, opportunities, and threats involved in a produce, project, person, business venture, or industry (Humphrey, 2005). Based on the documentary researches that have done before, this part will attempt to specify the internal environment characteristics and external environment elements, considering the impact of data mining technologies on managerial accounting and business administration, in order to assist business and technology alignment.

Table 2

SWOT Analysis of Data Mining Adoption

\begin{tabular}{|l|l|l|l|}
\hline Strengths & Weaknesses & Opportunities & Threats \\
\hline $\begin{array}{l}\text { Collaborative environment } \\
\text { (value chain) }\end{array}$ & $\begin{array}{l}\text { Integration with existing AIS } \\
\text { and/or MIS }\end{array}$ & Technology improvements & Systems maintenance \\
\hline Cost reduction & Data collection & $\begin{array}{l}\text { Administration process } \\
\text { reengineering }\end{array}$ & Data loss, data privacy \\
\hline $\begin{array}{l}\text { Information extraction and } \\
\text { analysis }\end{array}$ & Data storage, data migration & Decision support system & Security \\
\hline
\end{tabular}

Table 2 presents the main factors in SWOT analysis of data mining technologies impact on managerial accounting system. Using data mining and big data technologies within organizations has a significant impact 
on business strategy, business process, as well as business administration. In general, these technologies reshape the way in which enterprises make business.

\section{Strengths}

Strengths of adopting data mining technologies are as follows. It contributes to the collaboration of the value chain players. Information about the markets is extracted through big data approaches and algorithms, results in costs reduction and improves management capabilities.

\section{Weaknesses}

Weaknesses of integrating data mining technologies are mainly concentrated on the integration of organizations existing MIS and/or AIS. Historical data may be needed for format changing before getting into the data mining process. In addition, various information, such as fiscal and non-fiscal, numerical, and texts, has to be collected and stored for analysis.

\section{Opportunities}

Opportunities of adopting data mining technologies include the availability of new systems, such as business intelligence and executive decision support systems, and the chance for reengineering the business administration architecture and process. For big companies, it is preferable to build their own information center; for small companies, outsourcing service is another strategic option.

\section{Threats}

Threats of adopting data mining technologies are as follows. Concerning with the information gathering among value chain management, the data loss and privacy issues have to be taken into account. The back-up, data recovery, and confidentiality strategies and principles are needed before integrating new technology. In addition, the maintenance and security of IT systems are the main concerns as well.

\section{Expansion of Current AIS}

In order to extract, analyze, store, and present information, the AIS need to be complemented. There are a lot of new technologies which can be integrated into the current AIS, such as business intelligence and balanced scorecard systems (Grabski, Leech, \& Schmidt, 2011). The following will briefly discuss the possible expansions of AIS based on three sub-systems, i.e., data collection, data storage, and data processing.

Before data processing, it is important to obtain a rich supply of data sets, which are normally semi-structured or unstructured. For collecting the information of original invoices, one possible solution is the optical character recognition (OCR) technology, which can digitalize the images of handwritten or printed text into machine-encoded text (Lucas \& Amiri, 1996).

The large amount of data can be stored in Database Management Systems (DBMS) and data warehouses. Cloud service is another option; however, its security issues have to be taken into consideration (Ali, Khan, \& Vasilakos, 2015).

During data processing stage, data mining is the core technology. Methods previously discussed can be adopted, such as cluster analysis and OLAP. Statistical computing packages like R (language) can be useful as well (Schmidt, Ostrouchov, Chen, \& Patel, 2012). Some data mining tools and software providers include: enterprise miner from SAS, intelligent miner from IBM, setminer from SGI, clementine from SPSS, DB miner from DB Miner Technology Inc., PRW from Unica Technolgies Inc., Darwin from thinking machines, greenplum from EMC, etc. 


\section{Conclusions}

There are a few limitations and future research directions of this paper that need to be addressed before conclusion. First, this research is primarily based on documentary studies and SWOT analysis. From the methodology point of view, a more comprehensive and quantitative-based study is preferred for future study. Second, the technological influence on accounting professionals is not included. Third, the trend of convergence of financial accounting and management accounting can be identified, especially with the adoption of information technologies. The business process needs to be reengineered and the business architecture needs to be reshaped. Organizations become more flexible in doing business. These perspectives are considered to be research directions for future work.

Based on documentary studies and SWOT analysis, this paper identifies the challenges and opportunities when integrating data mining technologies into management accounting system. The findings are as follows:

(1) challenges: Information are gathering among value chain management. The back-up, data recovery, and privacy strategies and principles are necessary. In addition, the maintenance and security of IT systems are the main concerns as well.

(2) opportunities: Managerial accounting functions can be improved in three ways, i.e., cost management, performance evaluation and risk management, and planning and prediction. The enhanced managerial function would take a significant role in business decision-making process and therefore improve the level of business management capabilities. Besides, some possible complements of current AIS and MIS can be considered during the technological improvements.

Undoubtedly, business administration and management will benefit a lot from the new information technologies. These innovations include not only data mining, but also cloud computing and mobile technology. The alignment of IT and business will expand the research domain of Accounting and AIS, not only on possible changes of accountancy, but also on how the new technologies impact the role of accounting.

\section{References}

Ali, M., Khan, S. U., \& Vasilakos, A. V. (2015). Security in cloud computing: Opportunities and challenges. Information Sciences, 305, 357-383.

Association of Chartered Certified Accountants [ACCA] \& Institute of Management Accountants [IMA]. (2013). Digital Darwinism: Thriving in the face of technology change. Retrieved from http://www.accaglobal.com/content/dam/acca/global/PDF-technical/other-PDFs/Five-mins-on-Digital-Darwinism.pdf

Belfo, F., \& Trigo, A. (2013). Accounting information systems: Tradition and future directions. Procedia Technology, 9, 536-546.

Bellomi, F., Cuel, R., \& Biscaro, R. (2005). Ontology driven text mining for cost management processes. Proceedings from $S W A P$ 2005, Semantic Web Applications and Perspectives.

Bode, J. (1998). Decision support with neural networks in the management of research and development: Concepts and application to cost estimation. Information \& Management, 34(1), 33-40.

Chen, M., Mao, S., \& Liu, Y. (2014). Big data: A survey. Mobile Networks \& Applications, 19(2), 171-209.

Edwards, J. B. (2000). The new cost management culture: Where are we going? Journal of Corporate Accounting \& Finance, 11(3), 3-8.

Eklin, M., Arzi, Y., \& Shtub, A. (2009). Model for cost estimation in a finite-capacity stochastic environment based on shop floor optimization combined with simulation. European Journal of Operational Research, 194(1), 294-306.

Fayyad, U., Piatetsky-Shapiro, G., \& Smyth, P. (1996). From data mining to knowledge discovery in databases. American Association for Artificial Intelligence, 3, 37-54.

Grabski, S. V., Leech, S. A., \& Schmidt, P. J. (2011). A review of ERP research: A future agenda for accounting information systems. Journal of Information Systems, 25(1), 37-78.

Han, J., Kamber, M., \& Pei, J. (2012). Data mining: Concepts and techniques (3rd ed.). New York, NY: Morgan Kaufmann. 
Humphrey, A. (2005). SWOT analysis for management consulting. Retrieved from http://alumni.sri.com/newsletters/Dec-05.pdf Institute of Management Accountants [IMA]. (2008). Definition of management accounting. Retrieved from http://www.imanet.org/PDFs/Public/Research/SMA/Definition\%20of\%20Mangement\%20Accounting.pdf

Jans, M., Alles, M., \& Vasarhelyi, M. (2013). The case for process mining in auditing: Sources of value added and areas of application. International Journal of Account Information System, 14(1), 1-20.

Koutanaei, F. N., Sajedi, H., \& Khanbabaei, M. (2015). A hybrid data mining model of feature selection algorithms and ensemble learning classifiers for credit scoring. Journal of Retailing \& Consumer Services, 27, 11-23.

Koyuncugil, A. S., \& Ozgulbas, N. (2012). Financial early warning system model and data mining application for risk detection. Expert Systems With Applications, 39(6), 6238-6253.

Labrinidis, A., \& Jagadish, H. V. (2012). Challenges and opportunities with big data. Proceedings of the VLDB Endowment, 5(12), 2032-2033.

Lanen, W., Anderson, S. W., \& Maher, M. W. (2013). Fundamentals of cost accounting (4th ed.). New York, NY: McGraw-Hill.

Lankhorst, M. (2013). Enterprise architecture at work: Modelling, communication, and analysis. New York, NY: Springer.

Lucas, S., \& Amiri, A. (1996). Statistical syntactic methods for high-performance OCR. IEE Proceedings-Vision, Image and Signal Processing, 143(1), 23-30.

Lum, K. T., Baker, D. R., \& Hihn, J. M. (2008). The effects of data mining techniques on software cost estimation (IEMC Europe 2008, IEEE international, IEEE). Proceedings from Engineering Management Conference.

Medri, D. (2013). Big data \& business: An on-going revolution. Statistics views. Retrieved from http://www.statisticsviews.com/details/feature/5393251/Big-Data--Business-An-on-going-revolution.html

O’Brien, J. A., \& Marakas, G. M. (2011). Management information systems. New York, NY: McGraw-Hill.

Ortiz-Servin, J. J., Cadenas, J. M., Pelta, D. A., Castillo, A., \& Montes-Tadeo, J. L. (2015). Nuclear fuel lattice performance analysis by data mining techniques. Annals of Nuclear Energy, 80, 236-247.

Piatetsky-Shapiro, G., \& Frawley, W. J. (1991). Knowledge discovery in databases. Library Trends, 48, 1-13.

Professional Accountants in Business Committee. (2009). Evaluating and improving costing in organizations (international good practice guidance). Retrieved from http://www.fasab.gov/pdffiles/ifac_eval_and_improv_costing.pdf

Ren, X., Yan, D., \& Hong, T. (2015). Data mining of space heating system performance in affordable housing. Building \& Environment, 89, 1-13.

Sajadfar, N., \& Ma, Y. (2015). A hybrid cost estimation framework based on feature-oriented data mining approach. Advanced Engineering Informatics, 29(3), 633-647.

Schmidt, D., Ostrouchov, G., Chen, W. C., \& Patel, P. (2012). Tight coupling of R and distributed linear algebra for high-level programming with big data. High Performance Computing, Networking Storage and Analysis, SC Companion: IEEE, 113, 811-815.

Shi, S., Liu, C., Shen, Y., Yuan, C., \& Huang, Y. (2015). AutoRM: An effective approach for automatic web data record mining. Knowledge-Based Systems, 89, 314-331.

Tan, P., Steinbach, M., \& Kumar, V. (2011). Introduction to data mining (2nd ed.). New York, NY: Pearson.

Trigo, A., Varajão, J., Barroso, J., Soto-Acosta, P., Molina-Castillo, F. J., \& Gonzalvez-Gallego, N. (2011). Enterprise information systems adoption in Iberian large companies: Motivations and trends. In M. Tavana (Ed.), Managing adaptability, intervention, and people in enterprise information systems. Hershey, PA: IGI Global.

Varajão, J., Trigo, A., \& Barroso, J. (2009). Motivations and trends for IT/IS adoption: Insights from Portuguese companies. International Journal of Enterprise Information Systems (IJEIS), 5, 34-52.

Wijnmalen, D. J. D. (2007). Analysis of benefits, opportunities, costs, and risks (BOCR) with the AHP-ANP: A critical validation. Mathematical and Computer Modelling, 46(7), 892-905.

Williams, T. P., \& Gong, J. (2014). Predicting construction cost overruns using text mining, numerical data and ensemble classifiers. Automation in Construction, 43(43), 23-29.

Xing, W., Guo, R., Petakovic, E., \& Goggins, S. (2015). Participation-based student final performance prediction through interpretable genetic programming: Integrating learning analytics, educational data mining and theory. Computers in Human Behaviour: Learning Analytics, Educational Data Mining and Data-Driven, Educational Decision Making, 47, 168-181.

Zhou, L., Lu, D., \& Fujita, H. (2015). The performance of corporate financial distress prediction models with features selection guided by domain knowledge and data mining approaches. Knowledge-Based Systems, 85(C), 52-61.

Ziegler, C. N. (2012). Mining for strategic competitive intelligence: Foundations and applications. Berlin: Springer. 